\title{
Development of Down Syndrome Research Over the Last Decades-What Healthcare and Education Professionals Need to Know
}

\author{
Karin Windsperger ${ }^{1}$ and Stefanie Hoehl ${ }^{2 *}$ \\ ${ }^{1}$ Division of Obstetrics and Feto-Maternal Medicine, Department of Obstetrics and Gynecology, Medical University of Vienna, \\ Vienna, Austria, ${ }^{2}$ Research Unit Developmental Psychology, Department of Developmental and Educational Psychology, \\ Faculty of Psychology, University of Vienna, Vienna, Austria
}

OPEN ACCESS

Edited by:

Peter B. Marschik, University Medical Center

Göttingen, Germany

Reviewed by:

Dajie Marschik,

University Medical Center

Göttingen, Germany

Lisa A. Daunhauer, Colorado State University,

United States

André Frank Zimpel,

University of Hamburg, Germany

*Correspondence:

Stefanie Hoeh

stefanie.hoeh@univie.ac.at

Specialty section:

This article was submitted to Child and Adolescent Psychiatry,

a section of the journal

Frontiers in Psychiatry

Received: 28 July 2021 Accepted: 22 November 2021 Published: 14 December 2021

Citation:

Windsperger K and Hoehl S (2021) Development of Down Syndrome

Research Over the Last

Decades-What Healthcare and

Education Professionals Need to

Know. Front. Psychiatry 12:749046.

doi: 10.3389/fpsyt.2021.749046
Down syndrome (DS) is the most prevalent neurodevelopmental disorder, with a known genetic cause. Besides facial dysmorphologies and congenital and/or acquired medical conditions, the syndrome is characterized by intellectual disability, accelerated aging, and an increased likelihood of an early onset Alzheimer's disease in adulthood. These common patterns of DS are derived from the long-held standard in the field of DS research, that describes individuals with DS as a homogeneous group and compares phenotypic outcomes with either neurotypical controls or other neurodevelopmental disorders. This traditional view has changed, as modern research pinpoints a broad variability in both the occurrence and severity of symptoms across DS, arguing for DS heterogeneity and against a single "DS profile." Nevertheless, prenatal counseling does not often prioritize the awareness of potential within-group variations of DS, portraying only a vague picture of the developmental outcomes of children with DS to expectant parents. This mini-review provides a concise update on existent information about the heterogeneity of DS from a full-spectrum developmental perspective, within an interdisciplinary context. Knowledge on DS heterogeneity will not only enable professionals to enhance the quality of prenatal counseling, but also help parents to set targeted early interventions, to further optimize daily functions and the quality of life of their children.

Keywords: Down syndrome, trisomy 21, developmental outcome, phenotypic heterogeneity, Alzheimer's disease, medical comorbidities, social environment, prenatal counseling

\section{INTRODUCTION}

Down syndrome (DS) is the most common neurodevelopmental disorder with known genetic causes, and an incidence of 1 in 691 live births (1). This suggests that $\sim 417,000$ people with DS live in Europe (2). Currently, an expansive menu of prenatal diagnostic methods for DS is spreading worldwide, advancing the diagnosis of DS from postnatal to prenatal (3). Giving an expectant parent a fetal diagnosis of DS provides them with 2 options: keeping or terminating their pregnancy, following the lack of a cure (4). 
Prenatal counseling is crucial for providing parents with an accurate picture of DS so that informed decisions can be made in the context of their own beliefs and values (3). Although studies are still examining the nature of DS, portraying the expected neurodevelopmental outcomes of affected children remains challenging. Indeed, retrospective studies indicate that parents felt that the information received during prenatal counseling was inaccurate, outdated, and unbalanced, and either too negative or too optimistic (5-7). Without appropriate professional training or updated professional development regarding the individual variability in outcomes associated with DS, prenatal counselors might present expectant parents with inaccurate information or impressions. Therefore, expectant parents may not receive the level of information needed. Accordingly, all professionals working with families affected by DS must be aware of the most current scientific research regarding the heterogeneity of phenotypic outcomes (8).

This mini-review closes an existent literature gap by providing a concise update on the available information on withingroup variations in the DS phenotype of infants, children, and adolescents for professionals. First, a gross outline of DS research is given, focusing on the significant paradigm shift from a group- to an individual-level approach. Second, the current knowledge on significant within-group variations of DS in cognitive, behavioral, emotional, and olfactory functioning is summarized. Finally, the review concludes by arguing that only an interdisciplinary approach allows for the description of realistic individual DS profiles. The scope of this review is to further increase the awareness on DS heterogeneity concerning developmental outcomes.

\section{A PARADIGM SHIFT IN DS RESEARCH: FROM A GROUP- TO INDIVIDUAL-LEVEL APPROACH}

DS research dates back to 1866, when the English physician John Langdon Down systematically described the syndrome for the first time $(9,10)$. In addition to intellectual disability (ID), he chronicled a distinct physical phenotype of individuals with DS, conjecturing that they were "born to the same family" (page 9) $(10,11)$. The century following his pioneering work was filled with publications of diverse medical case studies documenting a range of physical traits and medical comorbidities, leading to various etiologies $(10,11)$.

Almost 100 years later, the French pediatrician and cytogeneticist, Jérôme Lejeune, identified the genetic basis of DS in 1959 as an extra copy of all or part of chromosome $21(10,12)$. The discovery of "trisomy 21 " paved the way for further research, to elucidate genotype-phenotype-relationships $(13,14)$. Since its original description, classical DS research has analyzed the syndrome's phenotypes relative to neurotypicals and/or other neurodevelopmental disorders, hence providing group-level data that have advanced our basic knowledge of DS (8). It is characterized by both typical physical features that make the syndrome "instantly recognizable" (page 8) and ID (11). Common appearance includes craniofacial dysmorphologies, short stature, low muscle tone, and a proportionally large tongue. Additionally, medical comorbidities, such as sleep apnea, visual and/or hearing problems, congenital heart defects, and altered behavioral, hematopoietic, endocrine, gastrointestinal, neurological, and musculoskeletal conditions, are linked to DS (10).

Most of these medical problems are treatable with pharmacotherapy and/or surgical interventions. Therefore, among the key focuses in recent DS research is the widespread field of neurocognition, associating DS with weaknesses in motor ability, auditory processing, verbal short-term memory, and expressive language. However, relative strengths in visuospatial processing, receptive language, and some aspects of social functioning have been reported (15-18). Further, DS is associated with accelerated aging and an increased likelihood of the early onset of Alzheimer's disease (AD) (18).

Although the generalizability of the characteristics of DS has been questioned repeatedly in the history of DS research, the group-level approach is a long-held standard (19, 20). However, this traditional view has changed, following a growing number of studies, which pinpoint significant within-group variations across individuals with DS at many levels of description. Pioneer studies have launched this paradigm shift, from a group to an individual-level approach, by highlighting significant individual differences in genetics, cell biology, brain research, and subsequently, parts of cognitive research on DS [see (8)]. These studies suggest that this heterogeneity may be continued in DS phenotypes (8). The following review aims to supplement the prevailing knowledge about the variability of the developmental outcomes of DS by addressing this issue from an interdisciplinary and applied science perspective, as this practical information may be the most useful for professionals to pass to expectant parents.

\section{INFANTS, CHILDREN, AND ADOLESCENTS WITH DS: VARIABILITY IN DEVELOPMENTAL OUTCOMES}

\section{Acquisition of Developmental Milestones}

Generally, it was assumed that infants and children with DS reached developmental milestones in the same linear fashion as their non-DS peers, but at later chronological ages. This view is too simplistic, as the age of acquiring milestones among infants and children with DS is reported to vary significantly $(21,22)$. For example, the mean age at the onset of babbling is $\sim 15$ months, with an interindividual variability of 10 months. Similarly, sphincter control is acquired by DS children at an approximate age of 44 months, with 22 months of interindividual variability (22). Notably, Locatelli et al. suggested that the age at which developmental milestones are reached influences the subsequent development of diverse cognitive domains significantly $(21,22)$.

\section{Intellectual Disability (ID)}

ID, defined by an intelligence quotient (IQ) score of $<70$, is reported to be universal in the DS population. However, this construct presents in DS with large interindividual variability (23). The majority of individuals with DS fall within the severe 
(IQ 20-35) to mild (IQ 50-69) range of ID. However, some cases reach IQ scores equivalent to children without ID $(14,24)$. Research on the developmental trajectories of cognitive function in neurotypicals shows that IQ is a construct that remains relatively stable and consistent across ages. A slight decline was observed only in older adults (14). Conversely, DS research has identified a linear decline in IQ scores as development progresses, starting in the first year of life (i.e., cognitive gains do not keep pace with chronological age). Notably, single IQ levels and the degree of cognitive decline vary across the DS group (14).

\section{Language}

Language is another cognitive domain that generates significant differences among individuals with DS. DS is associated with weaknesses in expressive language and a relative strength in the receptive language (18). The available literature reports developmental delays in both language domains, becoming apparent no later than age five, yet with wide individual differences $(25,26)$. Regarding vocabulary acquisition and growth, longitudinal studies reported an existing continuum, ranging from non-verbal children to those with a vocabulary close to the normal range $(27,28)$. Children with DS use gestures as a means of communication, which has been positively associated with the development of spoken vocabulary (29). Nevertheless, significant individual variability in the extent to which this "gestural advantage" is used has been demonstrated by empirical data (30). All within-group differences in language development persist into adulthood (26).

\section{Memory}

Memory and learning deficits are universal characteristics of DS and are known to become more pronounced as development progresses (14). In classical DS research, the findings of affected memory domains are mixed, suggesting underlying variability (18). Indeed, scientific data demonstrate that there are individual differences in both implicit and explicit memory $(8,31)$. Regarding the latter, significant within-group variations are described for short-term verbal and long-term visual memory (8). Individuals with DS often show deficits in processing local detail. Therefore, classical DS literature claims that individuals with DS were "global processors." However, this preference for global over local processing does not always occur in the DS population. Therefore, individuals with DS cannot be simply categorized into one of these processing styles (32).

\section{Executive Function (EF)}

EF encompasses a range of cognitive processes involved in goal-oriented behavior, and is a domain in which individuals with DS are shown to have pronounced difficulties (33). The areas of working memory, attention, planning, and inhibition are considered particularly challenging for individuals with DS; emotional control is considered a relative strength $(34,35)$. However, significant individual differences in EF across the DS group have become evident $(33,36)$. Within-group variations in auditory attention have been identified via electrophysiological measurement among toddlers with DS, data that also predict differences in language abilities as development progresses
(37). Patterns of executive dysfunction appear to be relatively consistent across development until adulthood $(23,34)$.

\section{Adaptive Behavior (AB)}

Children and adolescents with DS are known to be severely impaired in $\mathrm{AB}$, which subsumes behavioral skills that enable them to function independently in their everyday life $(23,38)$. Generally, $\mathrm{AB}$ encompasses 4 domains: socialization, communication, daily living, and motor skills (23). Significant within-group variations were apparent for all the 4 domains. For example, DS has been associated with sociability, friendliness, affection, empathy, good competence in forming relationships, and high tendency to smile (39). Yet, children and adolescents with DS are also considered stubborn, to show little accommodation to social partners, and approach strangers inappropriately (40). Some individuals with DS have even deficits in socialization to the extent of a comorbid diagnosis of autism (41).

\section{Maladaptive Behavior (MB) and Psychiatric Comorbidities}

$\mathrm{MB}$ encompasses a range of behaviors that impede an individual's activities of daily living or the ability to adjust to and participate in particular settings (23). Approximately $1 / 4$ to $1 / 3$ of individuals with DS exhibit clinically significant levels of maladaptive behavioral concerns (42-44). This behavioral construct is another domain that yields significant withingroup differences $(21,23,45)$. More difficulties with "anxiousdepressed" symptoms are observed among adolescents than younger children with DS (23). Children with DS often exhibit externalizing behavior (46). The manifestation of $\mathrm{MB}$ is significantly higher when neurobehavioral disorders are concomitant (47-49). According to the available literature, the manifestation of psychiatric features, including autism, depression, and the attention-deficit/hyperactivity disorder, vary significantly, between 6 and $>50 \%(42,44,50,51)$. Channell et al. underscored within-group differences in the behavioral domain by subtyping a $>300$-person DS group, hence identifying a separate "behavioral" class as described in Table 1 (23).

\section{Emotional Functioning}

The emotional profiles of individuals with DS have remained underexplored, which could be attributed to the assumed stereotype of high sociability in this population $(52,53)$. Available literature provides variable data about whether children and adolescents have difficulties in emotional functioning (52). Whereas, some studies negate differences in identifying basic emotion in faces between DS and non-DS groups, other scientific reports indicate that children and adolescents with DS have impairments in this emotional skill [see Roch et al. (52)] (54-57). Deficits in recognizing facial expressions were not generalized to all emotions, but mostly to fear $(52,58)$. Other studies report impairments in determining feelings, including surprise, anger, and neutral expression (40,58-61). Some studies pinpoint problems in ascertaining negative emotions (40). Moreover, an inability to distinguish between fear and sadness is another atypical pattern that has been reported among some individuals 
TABLE 1 | Characterization of the 3-class model of individuals with DS ( $N=314 ; 6-25$ years) based on the variability observed in cognitive and behavioral measures, identified by Channell et al. (23) using a latent profile analysis.

\begin{tabular}{llll}
\hline & & 3-class model proposed by Channell et al. (23) & Behavioral class \\
\cline { 2 - 4 } & Normative class & Cognitive class & $N=52(17 \%)$ \\
Number of participants & $N=153(48 \%)$ & $N=109(35 \%)$ & Cognitive skills (IQ, visuospatial \\
$\begin{array}{l}\text { Strengthens (relative to } \\
\text { sample average) }\end{array}$ & $\begin{array}{l}\text { Cognitive skills (IQ, visuospatial } \\
\text { abilities), adaptive behavior, } \\
\text { executive function }\end{array}$ & - & abilities), adaptive behavior \\
Weaknesses (relative to & - & Cognitive skills (IQ, visuospatial & Maladaptive behavior (ASD), \\
sample average) & & $\begin{array}{l}\text { abilities), executive function, } \\
\text { adaptive behavior, maladaptive }\end{array}$ & executive function
\end{tabular}

ASD, autism spectrum disorder; IQ, intelligence quotient.

(58). Most of these deficits are identified during infancy and childhood. Therefore, a negative impact on the subsequent development of interpersonal relationships is discussed (52). As previously mentioned, studies have exclusively gathered data at the group level. Moreover, further research should examine whether inconsistencies in findings across studies can be attributed to underlying within-group variations.

\section{Olfactory Functioning}

The number of studies on olfactory function among patients with DS is limited and relatively out of date (62-69). Historical studies have described olfactory deficits in the DS population for many years $(62,63,65,70)$. Because rhinologic pathologies have been ruled out by studies showing nasal function in DS as comparable to controls, central-nervous causes are suggested (64). More recently, Cecchini et al. described olfactory function as severely impaired among adults with DS (71). They found a positive correlation between odor identification and cognition (71). To date, the largest study, which included people with DS and under 18 years, described a minimal impairment of olfactory functioning among children and adolescents (9-17 years), which became pronounced in young adulthood (18-29 years) and was the lowest in adulthood (30-50 years) (72). Of the three groups, DS, IQ, and age-matched controls, significant within-group differences were evident only in the DS group (72). However, large and detailed analyses of olfactory function in light of within-group variations among children and adolescents with DS are still lacking. Odor identification deficits are considered a valid non-invasive early marker of AD. Therefore, future research on whether olfactory dysfunction can help to ascertain the subset of children and adolescents with DS that will later develop AD is warranted.

\section{Alzheimer's Disease (AD)}

Although the issue of $\mathrm{AD}$ appears outside the scope of this review, the following considerations must be made when the heterogeneity of DS is discussed with expectant parents from a full-spectrum developmental perspective. Owing to a shared genetic predisposition, individuals with DS have an increased likelihood of developing early onset AD in adulthood (18). Prevalence rates of dementia among the DS population vary significantly in the literature, from 8 to $100 \%(18,73)$. Recent brain research has identified Alzheimer's plaques among some children with DS, that is, as early as 8 years of age, whereas some DS brains show no plaques until early adulthood $(14,26)$. Although AD neuropathology occurs in virtually all individuals with DS over the age of 30 , only a subset of people develop clinical symptoms of dementia $(26,74,75)$. Hence, it is apparent that the widespread interindividual variability, typical for DS, is a pivotal feature not only during development, but also during aging (26). Aging is part of the continuous lifespan development. Accordingly, some authors argue that $\mathrm{AD}$ should be considered a disease that occurs during development, rather than aging (76).

\section{EXTRINSIC INFLUENCING FACTORS OF DEVELOPMENTAL OUTCOMES OF INFANTS, CHILDREN, AND ADOLESCENTS WITH DS}

\section{Medical Comorbidities}

In addition to cognitive limitations, parents must be informed that there is a list of medical comorbidities associated with DS. Some of them, including congenital heart defects (CHD), seizures, visual and/or hearing impairments, autism, and sleep disruptions, are known to moderate cognitive functioning (18). Analogous to neurodevelopmental outcomes, both the occurrence and expression of congenital and/or acquired medical complications are variable (18). For example, $41-56 \%$ of infants with DS are born with a CHD, with an atrioventricular septal defect that occurs between 31 and $61 \%$ being the most common form $(77,78)$. Cognition, gross motor skills, and language are significantly worse among infants with DS and CHD, relative to peers without $\mathrm{CHD}$, in some, but not in all related studies (7981). For example, Alsaied et al. showed that children with DS and $\mathrm{CHD}$, who undergo cardiac surgery during their first year, have no significant differences in neurodevelopmental outcomes at preschool and school age. However, as infants and toddlers, they were prone to poorer outcomes in receptive, expressive, and composite language compared to children with DS without $\mathrm{CHD}$, suggesting that deleterious effects may be dependent on clinical management (82). 


\section{Home Environment}

Another variable that affects the observed variability of DS phenotypes, which is influenced by the expectant parents, is the home environment. According to Karmiloff-Smith et al., the genetic syndrome changes the family context in terms of parentchild-interactions (8). D'Souza et al. demonstrated that parental depression, a disease linked to difficulties in responding to the child in a sensitive and consistent manner, explained deficits in expressive language development among children between 8 and 48 months of age with DS (83). Similarly, there is evidence that vocabulary development among children with DS is influenced by how parents respond to their children's communication. Deckers et al. argued that mothers with a higher level of education had a better ability to fine-tune their communication with their children with DS (28). Further demographic factors, including socioeconomic status, neighborhood demographics, and the availability of therapeutic resources, modulate the developmental outcomes of DS effectively $(84,85)$. These data demonstrate that only an interdisciplinary approach that considers psychological, physical, and social parameters will enable professionals to accurately inform expectant parents on how the DS phenotype will be expressed in each individual.

\section{DISCUSSION}

Although DS has been examined for a long time, that is 155 years, it is still one of the least understood genetic ID syndromes. The most significant reason for this is the high degree of phenotypic variability observed in the DS population, an issue that professionals are often unaware of when discussing the diagnosis with expectant parents. However, DS research has advanced from a group to an individual-level approach, attempting to acknowledge within-group differences at many levels of basic science (8). To expand on this wealth of data, this minireview has shed light on the available information on individual variability in the developmental outcomes of infants, children, and adolescents with DS from an applied science perspective, which will enhance the quality of prenatal counseling. Diverse developmental domains, including cognition, behavior, and emotional and olfactory functioning, have been discussed.

\section{REFERENCES}

1. Parker SE, Mai CT, Canfield MA, Rickard R, Wang Y, Meyer RE, et al. Updated National Birth Prevalence estimates for selected birth defects in the United States, 2004-2006. Birth Defects Res A Clin Mol Teratol. (2010) 88:1008-16. doi: 10.1002/bdra.20735

2. de Graaf G, Buckley F, Skotko BG. Estimation of the number of people with Down syndrome in Europe. Eur J Hum Genet. (2021) 29:402-10. doi: 10.1038/s41431-020-00748-y

3. Minear MA, Alessi S, Allyse M, Michie M, Chandrasekharan S. Noninvasive prenatal genetic testing: current and emerging ethical, legal, and social issues. Annu Rev Genomics Hum Genet. (2015) 16:369-98. doi: 10.1146/annurev-genom-090314-050000

4. Guedj F, Bianchi DW. Noninvasive prenatal testing creates an opportunity for antenatal treatment of Down syndrome. Prenat Diagn. (2013) 33:614-8. doi: $10.1002 / \mathrm{pd} .4134$
The evaluation of developmental outcomes from a fullspectrum perspective, however, must not only address different developmental domains, but also the change of phenotypes over time (86). Outcome variables are not completely intact or impaired uniformly throughout development, but manifest as variations at an early state, that may be magnified with age, ending up as either a strength or a weakness. Therefore, parents should be made aware that early development can be considered a critical window of opportunity to set adequate phenotype-specific interventions before deficits become severely pronounced (87). Thus, the maximization of individual potential is possible. In addition to psychological factors, other influencing variables must be considered by parents when the variability of DS phenotypes is discussed. According to Karmiloff-Smith who states that having a neurodevelopmental disorder changes both the social environment and physical status, only an interdisciplinary research approach can successfully describe valid profiles of individuals with DS (8).

The most convincing argument for emphasizing individual variability among DS groups and discussing them with expectant parents are both an average life expectancy of 60 years combined with an early onset of Alzheimer's disease in the DS population (18). Focusing on individual differences in the development of DS may be the best approach for exploring the risk and protective factors of $\operatorname{AD}(88,89)$.

Modern DS research shows that developmental heterogeneity has become increasingly validated (23). Moving forward, these up-to-date data must be disseminated under the supervision of professionals so that prenatal counseling can be optimized in quality, hence allowing parents to gain realistic expectations about the future of their children. Thus, more targeted treatments and interventions can be set to improve the daily function and quality of life.

\section{AUTHOR CONTRIBUTIONS}

KW and SH designed the paper. KW did the literature research and wrote the manuscript. SH provided intellectual input and critically revised the manuscript. Both authors contributed to the article and approved the submitted version.

5. Skotko BG, Kishnani PS, Capone GT, Group DSDS. Prenatal diagnosis of Down syndrome: how best to deliver the news. Am J Med Genet A. (2009) 149A:2361-7. doi: 10.1002/ajmg.a.33082

6. Zerres K, Rudnik-Schöneborn S, Holzgreve W. Do non-invasive prenatal tests promote discrimination against people with Down syndrome? What should be done? J Perinat Med. (2021) 49:965-71. doi: 10.1515/jpm-2021-0204

7. Skotko BG. With new prenatal testing, will babies with Down syndrome slowly disappear? Arch Dis Child. (2009) 94:823-6. doi: 10.1136/adc.2009.166017

8. Karmiloff-Smith A, Al-Janabi T, D’Souza H, Groet J, Massand E, Mok K, et al. The importance of understanding individual differences in Down syndrome. F1000Res. (2016) 5:389. doi: 10.12688/f1000research.7506.1

9. Down JL. Observations on an ethnic classification of idiots. Ment Retard. (1995) 33:54-6.

10. Hickey F, Hickey E, Summar KL. Medical update for children with Down syndrome for the pediatrician and family practitioner. Adv Pediatr. (2012) 59:137-57. doi: 10.1016/j.yapd.2012.04.006 
11. D W. Downs: The History of a Disability. Oxford: Oxford University Press (2011).

12. Lejeune J, Gautier M, Turpin R. Study of somatic chromosomes from 9 mongoloid children. C R Hebd Seances Acad Sci. (1959) 248:1721-2.

13. Patterson D, Costa AC. Down syndrome and genetics - a case of linked histories. Nat Rev Genet. (2005) 6:137-47. doi: 10.1038/nrg1525

14. Lukowski AF, Milojevich HM, Eales L. Cognitive functioning in children with down syndrome: current knowledge and future directions. Adv Child Dev Behav. (2019) 56:257-89. doi: 10.1016/bs.acdb.2019.01.002

15. Daunhauer LA, Fidler DJ. The down syndrome behavioral phenotype: implications for practice and research in occupational therapy. Occup Ther Health Care. (2011) 25:7-25. doi: 10.3109/07380577.2010.535601

16. Jarrold C, Baddeley AD. Short-term memory for verbal and visuospatial information in down's syndrome. Cogn Neuropsychiatry. (1997) 2:101-22. doi: 10.1080/135468097396351

17. Jarrold C, Baddeley AD, Phillips C. Down syndrome and the phonological loop: the evidence for, and importance of, a specific verbal short-term memory deficit. Downs Syndr Res Pract. (1999) 6:61-75. doi: 10.3104/reviews.97

18. Grieco J, Pulsifer M, Seligsohn K, Skotko B, Schwartz A. Down syndrome: cognitive and behavioral functioning across the lifespan. Am J Med Genet $C$ Semin Med Genet. (2015) 169:135-49. doi: 10.1002/ajmg.c.31439

19. Desai SS. Down syndrome: a review of the literature. Oral Surg Oral Med Oral. (1997) 84:279-85. doi: 10.1016/S1079-2104(97)90343-7

20. Hodapp RM. Studying interactions, reactions, and perceptions: can genetic disorders serve as behavioral proxies? J Autism Dev Disord. (2004) 34:29-34. doi: 10.1023/B:JADD.0000018071.02942.00

21. van Gameren-Oosterom HB, Fekkes M, Buitendijk SE, Mohangoo AD, Bruil J, Van Wouwe JP. Development, problem behavior, and quality of life in a population based sample of eight-year-old children with Down syndrome. PLoS ONE. (2011) 6:e21879. doi: 10.1371/journal.pone.0021879

22. Locatelli C, Onnivello S, Antonaros F, Feliciello A, Filoni S, Rossi S, et al. Is the age of developmental milestones a predictor for future development in down syndrome? Brain Sci. (2021) 11:655. doi: 10.3390/brainsci11050655

23. Channell MM, Mattie LJ, Hamilton DR, Capone GT, Mahone EM, Sherman SL, et al. Capturing cognitive and behavioral variability among individuals with Down syndrome: a latent profile analysis. J Neurodev Disord. (2021) 13:16. doi: 10.1186/s11689-021-09365-2

24. Edgin JO. Cognition in Down syndrome: a developmental cognitive neuroscience perspective. Wiley Interdiscip Rev Cogn Sci. (2013) 4:307-17. doi: $10.1002 /$ wcs. 1221

25. Guralnick MJ. Involvement with peers: comparisons between young children with and without Down's syndrome. J Intellect Disabil Res. (2002) 46(Pt 5):379-93. doi: 10.1046/j.1365-2788.2002.00405.x

26. Thomas MSC, Ojinaga Alfageme O, D'Souza H, Patkee PA, Rutherford MA, Mok KY, et al. A multi-level developmental approach to exploring individual differences in Down syndrome: genes, brain, behaviour, and environment. Res Dev Disabil. (2020) 104:103638. doi: 10.1016/j.ridd.2020.103638

27. Zampini L, D'Odorico L. Communicative gestures and vocabulary development in 36-month-old children with Down's syndrome. Int J Lang Commun Disord. (2009) 44:1063-73. doi: 10.1080/13682820802398288

28. Deckers SRJM, Van Zaalen Y, Van Balkom H, Verhoeven L. Predictors of receptive and expressive vocabulary development in children with Down syndrome. Int J Speech Lang Pathol. (2019) 21:10-22. doi: 10.1080/17549507.2017.1363290

29. Özçalişkan S, Adamson LB, Dimitrova N, Baumann S. Early gesture provides a helping hand to spoken vocabulary development for children with autism, Down syndrome and typical development. J Cogn Dev. (2017) 18:325-37. doi: 10.1080/15248372.2017.1329735

30. Kaat-van den Os D, Volman C, Jongmans M, Lauteslager P. Expressive vocabulary development in children with down syndrome: a longitudinal study. J Policy Pract Intellect Disabil. (2016) 14:311-8. doi: 10.1111/jppi.12212

31. Vicari S. Implicit versus explicit memory function in children with Down and Williams syndrome. Downs Syndr Res Pract. (2001) 7:35-40. doi: $10.3104 /$ reports.112

32. D’Souza D, Booth R, Connolly M, Happé F, Karmiloff-Smith A. Rethinking the concepts of 'local or global processors': evidence from Williams syndrome, Down syndrome, and Autism Spectrum Disorders. Dev Sci. (2016) 19:452-68. doi: $10.1111 /$ desc. 12312
33. Tungate AS, Conners FA. Executive function in Down syndrome: a metaanalysis. Res Dev Disabil. (2021) 108:103802. doi: 10.1016/j.ridd.2020.103802

34. Loveall SJ, Conners FA, Tungate AS, Hahn LJ, Osso TD. A cross-sectional analysis of executive function in Down syndrome from 2 to 35 years. J Intellect Disabil Res. (2017) 61:877-87. doi: 10.1111/jir.12396

35. Lee NR, Anand P, Will E, Adeyemi EI, Clasen LS, Blumenthal JD, et al. Everyday executive functions in Down syndrome from early childhood to young adulthood: evidence for both unique and shared characteristics compared to youth with sex chromosome trisomy (XXX and XXY). Front Behav Neurosci. (2015) 9:264. doi: 10.3389/fnbeh.2015.00264

36. Grealish KG, Price AM, Stein DS. Systematic review of recent pediatric down syndrome neuropsychology literature: considerations for regression assessment and monitoring. J Dev Behav Pediatr. (2020) 41:486-95. doi: 10.1097/DBP.0000000000000800

37. D’Souza D, D’Souza H, Johnson MH, Gliga T, Kushnerenko E, Scerif G, et al. Are early neurophysiological markers of ASD syndrome-specific? A cross-syndrome comparison. In: Paper presented at the XIX Biennial International Conference on Infant Studies. Berlin: International Society on Infant Studies (2014).

38. de Weger C, Boonstra FN, Goossens J. Differences between children with Down syndrome and typically developing children in adaptive behaviour, executive functions and visual acuity. Sci Rep. (2021) 11:7602. doi: 10.1038/s41598-021-85037-4

39. Fidler DJ. The emerging Down syndrome behavioral phenotype in early childhood. Infants Young Child. (2005) 18:86-103. doi: 10.1097/00001163-200504000-00003

40. Porter MA, Coltheart M, Langdon R. The neuropsychological basis of hypersociability in Williams and Down syndrome. Neuropsychologia. (2007) 45:2839-49. doi: 10.1016/j.neuropsychologia.2007.05.006

41. Glennon JM, Karmiloff-Smith A, Thomas MSC. Syndromic autism: progressing beyond current levels of description. Rev J Autism Dev Disord. (2017) 4:321-7. doi: 10.1007/s40489-017-0116-2

42. Dykens EM. Psychiatric and behavioral disorders in persons with Down syndrome. Ment Retard Dev Disabil Res Rev. (2007) 13:272-8. doi: 10.1002/mrdd.20159

43. Coe DA, Matson JL, Russell DW, Slifer KJ, Capone GT, Baglio C, et al. Behavior problems of children with Down syndrome and life events. J Autism Dev Disord. (1999) 29:149-56. doi: 10.1023/A:1023044711293

44. Roizen NJ, Patterson D. Down's syndrome. Lancet. (2003) 361:1281-9. doi: 10.1016/S0140-6736(03)12987-X

45. van Gameren-Oosterom HB, Fekkes M, van Wouwe JP, Detmar SB, Oudesluys-Murphy AM, Verkerk PH. Problem behavior of individuals with Down syndrome in a nationwide cohort assessed in late adolescence. J Pediatr. (2013) 163:1396-401. doi: 10.1016/j.jpeds.2013.06.054

46. Dykens EM, Shah B, Sagun J, Beck T, King BH. Maladaptive behaviour in children and adolescents with Down's syndrome. J Intellect Disabil Res. (2002) 46(Pt 6):484-92. doi: 10.1046/j.1365-2788.2002.00431.x

47. Capone GT, Grados MA, Kaufmann WE, Bernad-Ripoll S, Jewell A. Down syndrome and comorbid autism-spectrum disorder: characterization using the aberrant behavior checklist. Am J Med Genet A. (2005) 134:373-80. doi: 10.1002/ajmg.a.30622

48. Carter JC, Capone GT, Gray RM, Cox CS, Kaufmann WE. Autistic-spectrum disorders in Down syndrome: further delineation and distinction from other behavioral abnormalities. Am J Med Genet B Neuropsychiatr Genet. (2007) 144B:87-94. doi: 10.1002/ajmg.b.30407

49. Ji NY, Capone GT, Kaufmann WE. Autism spectrum disorder in Down syndrome: cluster analysis of Aberrant Behaviour Checklist data supports diagnosis. J Intellect Disabil Res. (2011) 55:1064-77. doi: 10.1111/j.1365-2788.2011.01465.x

50. Siegel MS, Smith WE. Psychiatric features in children with genetic syndromes: toward functional phenotypes. Pediatr Clin North Am. (2011) 58:833-64. doi: 10.1016/j.pcl.2011.06.010

51. Capone G, Goyal P, Ares W, Lannigan E. Neurobehavioral disorders in children, adolescents, and young adults with Down syndrome. Am J Med Genet C Semin Med Genet. (2006) 142C:158-72. doi: 10.1002/ajmg.c.30097

52. Roch M, Pesciarelli F, Leo I. How individuals with down syndrome process faces and words conveying emotions? Evidence From a Priming Paradigm. Front Psychol. (2020) 11:692. doi: 10.3389/fpsyg.2020.00692 
53. Pitcairn TK, Wishart JG. Reactions of young children with Down's syndrome to an impossible task. Br J Dev Psychol. (1994) 12:485-9. doi: 10.1111/j.2044-835X.1994.tb00649

54. Turk J, Cornish K. Face recognition and emotion perception in boys with fragile-X syndrome. J Intellect Disabil Res. (1998) 42:490-9. doi: 10.1046/j.1365-2788.1998.4260490.x

55. Celani G, Battacchi MW, Arcidiacono L. The understanding of the emotional meaning of facial expressions in people with autism. J Autism Dev Disord. (1999) 29:57-66. doi: 10.1023/A:1025970600181

56. Goldman KJ, Shulman C, Bar-Haim Y, Abend R, Burack JA. Attention allocation to facial expressions of emotion among persons with Williams and Down syndromes. Dev Psychopathol. (2017) 29:1189-97. doi: 10.1017/S0954579416001231

57. Martínez-Castilla P, Burt M, Borgatti R, Gagliardi C. Facial emotion recognition in Williams syndrome and Down syndrome: a matching and developmental study. Child Neuropsychol. (2015) 21:668-92. doi: 10.1080/09297049.2014.945408

58. Wishart JG, Cebula KR, Willis DS, Pitcairn TK. Understanding of facial expressions of emotion by children with intellectual disabilities of differing aetiology. J Intellect Disabil Res. (2007) 51(Pt 7):551-63. doi: 10.1111/j.1365-2788.2006.00947.x

59. Hippolyte L, Barisnikov K, Van der Linden M. Face processing and facial emotion recognition in adults with Down syndrome. Am J Ment Retard. (2008) 113:292-306. doi: 10.1352/0895-8017(2008)113[292:FPAFER]2.0.CO;2

60. Kasari C, Freeman SF, Hughes MA. Emotion recognition by children with Down syndrome. Am J Ment Retard. (2001) 106:59-72. doi: 10.1352/08958017(2001)106<0059:ERBCWD>2.0.CO;2

61. Wishart JG, Pitcairn TK. Recognition of identity and expression in faces by children with Down syndrome. Am J Ment Retard. (2000) 105:466-79. doi: 10. 1352/0895-8017(2000) 105<0466:ROIAEI > 2.0.CO;2

62. Murphy C, Jinich S. Olfactory dysfunction in Down's Syndrome. Neurobiol Aging. (1996) 17:631-7. doi: 10.1016/0197-4580(96)00008-5

63. Hemdal P, Corwin J, Oster H. Olfactory identification deficits in Down's syndrome and idiopathic mental retardation. Neuropsychologia. (1993) 31:977-84. doi: 10.1016/0028-3932(93)90152-P

64. Chen MA, Lander TR, Murphy C. Nasal health in Down syndrome: a cross-sectional study. Otolaryngol Head Neck Surg. (2006) 134:741-5. doi: 10.1016/j.otohns.2005.12.035

65. Warner MD, Peabody CA, Berger PA. Olfactory deficits and Down's syndrome. Biol Psychiatry. (1988) 23:836-9. doi: 10.1016/0006-3223(88)90073-X

66. Zucco GM, Negrin NS. Olfactory deficits in Down subjects: a link with Alzheimer disease. Percept Mot Skills. (1994) 78:627-31. doi: $10.2466 / \mathrm{pms}$.1994.78.2.627

67. McKeown DA, Doty RL, Perl DP, Frye RE, Simms I, Mester A. Olfactory function in young adolescents with Down's syndrome. J Neurol Neurosurg Psychiatry. (1996) 61:412-4. doi: 10.1136/jnnp.61.4.412

68. Wetter S, Murphy C. Individuals with Down's syndrome demonstrate abnormal olfactory event-related potentials. Clin Neurophysiol. (1999) 110:1563-9. doi: 10.1016/S1388-2457(99)00086-3

69. Sliger M, Lander T, Murphy C. Effects of the ApoE epsilon4 allele on olfactory function in Down syndrome. J Alzheimers Dis. (2004) 6:397-402; discussion 43-9. doi: 10.3233/JAD-2004-6407

70. Brousseau K, Brainerd MG. A Study of the Physical and Mental Characteristics of Mongoloid Imbeciles. Baltimore: Williams and Wilkins (1928). doi: 10.1097/00000441-192808000-00020

71. Cecchini MP, Viviani D, Sandri M, Hähner A, Hummel T, Zancanaro C. Olfaction in people with down syndrome: a comprehensive assessment across four decades of age. PLoS ONE. (2016) 11:e0146486. doi: 10.1371/journal.pone.0146486

72. Nijjar RK, Murphy C. Olfactory impairment increases as a function of age in persons with Down syndrome. Neurobiol Aging. (2002) 23:65-73. doi: 10.1016/S0197-4580(01)00263-9

73. Zigman WB, Lott IT. Alzheimer's disease in Down syndrome: neurobiology and risk. Ment Retard Dev Disabil Res Rev. (2007) 13:237-46. doi: $10.1002 / \operatorname{mrdd} .20163$

74. Head E, Silverman W, Patterson D, Lott IT. Aging and down syndrome. Curr Gerontol Geriatr Res. (2012) 2012:412536. doi: 10.1155/2012/412536
75. Head E, Powell D, Gold BT, Schmitt FA. Alzheimer's disease in down syndrome. Eur J Neurodegener Dis. (2012) 1:353-64.

76. Karmiloff-Smith A. What Can Studying Babies With Down Syndrome Possibly Tell Us About Alzheimer's Disease in Adults? UCSD Dart Neuroscience Seminar. Retrieved from: https://tdlcucsdedu/research/DNS/ videos/Karmiloff-Smithmp4 (accessed August 28, 2019).

77. Torfs CP, Christianson RE. Anomalies in Down syndrome individuals in a large population-based registry. Am J Med Genet. (1998) 77:431-8. doi: 10.1002/(SICI)1096-8628(19980605)77:5<431::AID-AJMG15>3.0.CO;2J

78. Freeman SB, Bean LH, Allen EG, Tinker SW, Locke AE, Druschel C, et al. Ethnicity, sex, and the incidence of congenital heart defects: a report from the National Down Syndrome Project. Genet Med. (2008) 10:173-80. doi: 10.1097/GIM.0b013e3181634867

79. Visootsak J, Mahle WT, Kirshbom PM, Huddleston L, Caron-Besch M, Ransom A, et al. Neurodevelopmental outcomes in children with Down syndrome and congenital heart defects. Am J Med Genet A. (2011) 155A:268891. doi: 10.1002/ajmg.a.34252

80. Visootsak J, Huddleston L, Buterbaugh A, Perkins A, Sherman S, Hunter J. Influence of CHDs on psycho-social and neurodevelopmental outcomes in children with Down syndrome. Cardiol Young. (2016) 26:250-6. doi: 10.1017/S1047951115000062

81. Startin CM, D'Souza H, Ball G, Hamburg S, Hithersay R, Hughes KMO, et al. Health comorbidities and cognitive abilities across the lifespan in Down syndrome. J Neurodev Disord. (2020) 12:4. doi: 10.1186/s11689-019-9306-9

82. Alsaied T, Marino BS, Esbensen AJ, Anixt JS, Epstein JN, Cnota JF. Does congenital heart disease affect neurodevelopmental outcomes in children with down syndrome? Congenit Heart Dis. (2016) 11:26-33. doi: $10.1111 /$ chd.12322

83. D'Souza H, Lathan A, Karmiloff-Smith A, Mareschal D. Down syndrome and parental depression: A double hit on early expressive language development. Res Dev Disabil. (2020) 100:103613. doi: 10.1016/j.ridd.2020.103613

84. Cebula KR, Moore DG, Wishart JG. Social cognition in children with Down's syndrome: challenges to research and theory building. J Intellect Disabil Res. (2010) 54:113-34. doi: 10.1111/j.1365-2788.2009.01215.x

85. Moore DG, Oates JM, Hobson RP, Goodwin J. Cognitive and social factors in the development of infants with Down syndrome. Downs Syndr Res Pract. (2002) 8:43-52. doi: 10.3104/reviews.129

86. Karmiloff-Smith A, Grant J, Berthoud I, Davies M, Howlin P, Udwin O. Language and Williams syndrome: how intact is "intact"? Child Dev. (1997) 68:246-62. doi: 10.1111/j.1467-8624.1997.tb01938.x

87. Karmiloff-Smith A. Development itself is the key to understanding developmental disorders. Trends Cogn Sci. (1998) 2:389-98. doi: 10.1016/S1364-6613(98)01230-3

88. Lott IT, Head E. Dementia in Down syndrome: unique insights for Alzheimer disease research. Nat Rev Neurol. (2019) 15:135-47. doi: 10.1038/s41582-018-0132-6

89. Hithersay R, Startin CM, Hamburg S, Mok KY, Hardy J, Fisher EMC, et al. Association of Dementia With Mortality Among Adults With Down Syndrome Older Than 35 Years. JAMA Neurol. (2019) 76:152-60. doi: 10.1001/jamaneurol.2018.3616

Conflict of Interest: The authors declare that the research was conducted in the absence of any commercial or financial relationships that could be construed as a potential conflict of interest.

Publisher's Note: All claims expressed in this article are solely those of the authors and do not necessarily represent those of their affiliated organizations, or those of the publisher, the editors and the reviewers. Any product that may be evaluated in this article, or claim that may be made by its manufacturer, is not guaranteed or endorsed by the publisher.

Copyright (C) 2021 Windsperger and Hoehl. This is an open-access article distributed under the terms of the Creative Commons Attribution License (CC BY). The use, distribution or reproduction in other forums is permitted, provided the original author(s) and the copyright owner(s) are credited and that the original publication in this journal is cited, in accordance with accepted academic practice. No use, distribution or reproduction is permitted which does not comply with these terms. 